\title{
Production Characteristics of Dunaliella salina at Two-Phase Pilot Cultivation (Crimea)
}

\author{
Andrey B. Borovkov', Irina N. Gudvilovich ${ }^{1}$, Anna L. Avsiyan ${ }^{1, *}{ }^{(\mathbb{B}}$, Olga A. \\ Memetshaeva $^{1}$, Alexander S. Lelekov ${ }^{1}$, Tatyana M. Novikova ${ }^{1}$
}

${ }^{1}$ A.O. Kovalevsky Institute of Biology of the Southern Seas of RAS Department of Biotechnology and Phytoresources Nakhimov ave., 299011, Sevastopol, Russia.

\section{Article History}

Received 23 October 2019

Accepted 14 June 2019

First Online 05 November 2019

\section{Corresponding Author}

Tel.: +7 8692550795

E-mail: anna.I.avsiyan@gmail.com

\section{Keywords \\ Dunaliella \\ Batch culture \\ Two-phase growth mode \\ Productivity \\ Carotenoids}

\begin{abstract}
Productional and biochemical characteristics of green alga Dunaliella salina (Dunal) Teodoresco were studied during pilot cultivation at the south-west of Crimean Peninsula, Russia. Two-phase cultivation was carried out in ponds located in the greenhouse module. In the "green" phase, biomass concentration reached $1.2 \mathrm{~g} / \mathrm{l}$, with maximum cell density of $1.69 \cdot 10^{6} \mathrm{cell} / \mathrm{ml}$ and the maximum productivity of 0.08 $\mathrm{g} /\left(\right.$ ( -day) $\left(7 \mathrm{~g} /\left(\mathrm{m}^{2}\right.\right.$.day $\left.)\right)$. Twofold culture dilution was applied for carotenogenesis induction. The maximum cell density in the "red" phase was $0.84 \cdot 10^{6} \mathrm{cell} / \mathrm{ml}$, while biomass reached $0.95 \mathrm{~g} / \mathrm{l}$. Mean net carotenoid accumulation rate at the second stage (1-6 day) was $0.65 \mathrm{mg} /(1 \cdot$ day). Carotenoids content in culture doubled compared to initial values and reached about $20 \mathrm{mg} / \mathrm{l}$ or $800 \mathrm{mg} / \mathrm{m}^{2}$. Carotenoids/chlorophyll $a$ ratio of 11.6 was observed by the end of the "red" phase. Night biomass loss was higher in the "red" phase (up to 9.5\% of biomass) compared to the "green" phase (up to 5.6\%). Optimal duration of both the first and the second cultivation stages was found to be 10-12 days for the studied weather conditions, which enables production of $3 \mathrm{~g}$ of carotenoids from $1 \mathrm{~m}^{2}$ (100 I) of starter culture. In conclusion, Crimea is a prospective region for $D$. salina algobiotechnology.
\end{abstract}

\section{Introduction}

Green halophilic microalga Dunaliella salina (Dunal) Teodoresco is widely known and interesting species due to its high tolerance to extreme conditions of salinity, light, temperature and $\mathrm{pH}$, as well as the abundance of synthesized biologically active compounds such as carotenoids, glycerin, lipids and many others (Oren, 2005; Ben-Amotz, Polle, \& Rao, 2009). Microalgal cells are able to accumulate a significant amount of $\beta$-carotene when exposed to stress factors, thereby Dunaliella biomass is widely used as a provitamin supplement for livestock breeding, aquaculture, production of food additives, food pigments, as well as an additive to food and cosmetic products with antioxidant properties (Borowitzka, 2013;
Sathasivam \& Ki, 2018). Along with $\beta$-carotene, D. salina synthesizes lutein and other carotenoids (GarcíaGonzález, Moreno, Manzano, Florencio, \& Guerrero, 2005). In addition, $D$. salina extracts are able to exhibit antimicrobial activity (Kilic, Erdem, \& Donmez, 2019).

The growth rate decreases under stress conditions that induce the accumulation of $\beta$-carotene, so that the attainment of high density Dunaliella culture is not possible (Prieto, Canavate, \& García-González, 2011). Therefore, one of the most common methods of industrial production of its biomass enriched with $\beta$ carotene is two-phase cultivation proposed by BenAmotz (1995). At the first "green" phase favourable conditions are created for high growth rate maintenance, thereby, biomass accumulation occurs. Then, at the second "red" phase, carotenogenesis is 
induced in $D$. salina cells by different stress factors, such as salinity and illumination increase, mineral nutrient limiting (Solovchenko et al., 2015; Lv et al., 2016; Minhas, Hodgson, Barrow, \& Adholeya, 2016; Hamed, Ak, Isık, \& Uslu, 2017; Achour, Doumandji, Bouras, Sabaou, \& Assunção, 2019).

The use of natural solar illumination for cultivation enables the efficient use of natural resources (Del Campo, García-González, \& Guerrero, 2007). However, when Dunaliella is grown under natural light-dark regimen night biomass loss (NBL) has to be taken into account in overall production balance. NBL occurs due to cell respiration, exometabolites excretion to the medium and cell death (Giordano, Davis, \& Bowes, 1994; García-González et al., 2003). It was shown that when $D$. salina is cultivated in laboratory conditions (photoperiod 16 : $8 \mathrm{~h}$, light : dark) NBL can be $2.5-32 \%$ of the biomass and $16-75 \%$ of the production for the previous light period, depending on the growth stage of the batch culture and illumination (Avsiyan, 2014). Also due to respiratory consumption of reserve compounds in the cell during dark period the relationship between basic biochemical cell compounds (reserve and structural carbohydrates, proteins, lipids, pigments, glycerol) changes and cell volume decreases (Bonnefond, Moelants, Talec, Bernard, \& Sciandra, 2016; Xu, Ibrahim, \& Harvey, 2016). Nevertheless, along with catabolic processes, the photosynthetic apparatus recovery occurs in the dark after photoinhibition (Polle \& Melis, 1999).

Because of the need for high light intensity to maximize $\beta$-carotene production beyond what is required for normal growth, production facilities are located in areas where solar energy is maximal and cloud cover is minimal. In most cases, existing Dunaliella producing facilities are close to available salt water sources (Tran, Doan, Louime, Giordano, \& Portilla, 2014), e.g. the marine/lake-salt industry, mainly in sunny and warm climate (USA, Israel, China, Australia, Japan, India) (Ben-Amotz, 2003; Borowitzka, 2013). Possibility of $D$. salina cultivation was studied at Spain (García-González et al., 2003), Iran (Tafreshi \& Shariati, 2006), UAE (Kitto \& Resinald, 2011), Thailand (Wu et al., 2017).

In nature, favourable conditions for $D$. salina blooms occur in hypersaline reservoirs. Crimean Peninsula (south of Russia) is a part of its natural habitat. There are a lot of hypersaline reservoirs and saltproducing enterprises within its territory, with high insolation at the summer time, which promotes carotenoids accumulation in algae (Massyuk, 1973). Crimean climate is mainly warm humid continental (Dfa) with warm oceanic (Cfa) and temperate oceanic (Cfb) areas in the South (Peel, Finlayson, \& McMahon, 2007). Crimea receives about $10 \%$ of the annual light energy amount in winter, $30 \%$ in the spring, $40 \%$ in summer and $20 \%$ in autumn. The largest amount of solar energy is received by the Crimea in summer (up to 2095 $\mathrm{MJ} /\left(\right.$ season $\left.\cdot \mathrm{m}^{2}\right)$, and its maximum amount falls on the south-western coast of Crimea, where our experiment was conducted (Terez, Terez, Kozak, Kuzmin, \& Dolgii, 2012). Despite the favorable conditions for the growth in natural water bodies and salt basins, the concentration of $D$. salina biomass and $\beta$-carotene in them is significantly lower than in intensive laboratory cultures (Borovkov \& Gudvilovich, 2015). Due to the availability of hypersaline water and salt-producing enterprises, as well as suitable climatic conditions, the Crimean Peninsula is promising for industrial cultivation of $D$. salina and production of carotenoids (Massyuk, 1973).

In this respect, the aim of this research was to study the growth and biochemical characteristics of the carotenogenic microalgae $D$. salina to determine its production potential during pilot two-stage cultivation in the south-west of Crimean Peninsula (Sevastopol).

\section{Materials and Methods}

\section{Strain and Culture Conditions}

In present study, unialgal culture of Dunaliella salina (Dunal) Teodoresco, 1905 was used (strain IMBR2 from A.O. Kovalevsky Institute of Biology of the Southern Seas of RAS (IBSS) common use center "World Ocean hydrobionts collection", Sevastopol, Russia). Microalgal culture was grown on the modified culture medium according to Shaish, Avron and Ben-Amotz (1990). Modification involved adding of sea salt ("Galit", Russia) up to $120 \mathrm{~g} / \mathrm{l}$ concentration. Pilot scale study was carried out at the premises of Biotechnology and Phytoresources Department, IBSS, Sevastopol, Russia

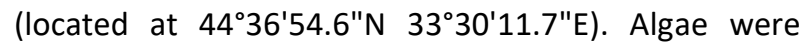
grown in pilot algobiotechnologal greenhouse module made of polycarbonate that provided protection from possible atmospheric precipitation and temperature maintaining. Square ponds $(1 \times 1 \mathrm{~m})$ were covered with polyethylene film and layed on the leveled ground. Culture of $D$. salina maintained in greenhouse module during previous winter and spring period was used as the inoculate. Cell suspension was continuously stirred by aquarium pump Atman AT-201 (Chuangxing Electrical Appliances Co., Ltd, China). Temperature and illumination level were natural without alterations. Illuminance level on the pond surface was registered by automatic measuring sensor based on Arduino Nano platform (Chekushkin, Lelekov \& Trenkenshu, 2018). CdS photoresistor GL12516 was the main sensor unit. Data were registered at Micro SD memory card at fixed time intervals. The sensor was calibrated to standard luxmeter U-116 (ProfKiP, Russia). Measurements data of diurnal variations of ponds surface illuminance during four days of experiment are shown at Figure 1 . Photoperiod was $15 \mathrm{~h}: 9 \mathrm{~h}$ (day : night) at average. The maximal illuminance reached $70-80 \mathrm{klx}$. The average illuminance during daytime was about 30-40 klx.

In the first cultivation phase the inoculate and culture medium were mixed (with the ratio 1:1.5 and 
batch culture was grown in the ponds for 27 days. In the second cultivation phase Dunaliella culture was diluted twofold with fresh culture medium lacking nitrogen and phosphorous salts. Culture layer depth was $9 \mathrm{~cm}$ in the first stage and $4 \mathrm{~cm}$ in the second stage, culture volume was $90 \mathrm{I}$ and $40 \mathrm{I}$ respectively.

\section{Growth Measurements}

D. salina culture growth was registered photometrically (Gevorgiz, Alisievich, \& Shmatok, 2005). Microalgal suspension optical density at $750 \mathrm{~nm}\left(D_{750}\right)$ was measured by Unico 2100 photometer (United Products \& Instruments, USA) in with $5 \mathrm{~mm}$ pathway cuvettes; absolute measurement error did not exceed $1.0 \%$.

Optical density units (o.d.u.) ( $D_{750}$ ) were converted to biomass dry weight $(D W)$ values by calculation according to the equation:

$$
D W=k \times D_{750},
$$

where $D W$ is biomass dry weight; $D_{750}$ is culture optical density; $k$ is conversion factor. Empirical factor $k$ $=0,78 \mathrm{~g} /(\mathrm{l} \cdot \mathrm{o} . \mathrm{d}$.u. $)$ was defined previously.

Cell density $(N$, cell $/ \mathrm{ml})$ counts were made with hemocytometer (Gorjayev's chamber, MiniMed, Russia) using light microscope Carl Zeiss Axiostar Plus (Carl Zeiss company, Germany) (Absher, 1973).

Maximal productivity $\left(P_{m}\right)$ was calculated by approximating growth curve in the linear growth phase area on the basis of biomass $(B)$ and cell number $(N)$ :

$$
\begin{gathered}
B=B_{l}+P_{m} \times\left(t-t_{l}\right), \\
N=N_{l}+P_{m} \times\left(t-t_{l}\right)
\end{gathered}
$$

where $B_{l}$ is culture density at the beginning of linear growth phase; $N_{I}$-cell density; $t_{l}$ is the time at the beginning of linear growth phase (Lelekov, Trenkenshu, 2007).

Total night biomass loss (NBL) as fraction of biomass at the end of light period $\left(L_{B}\right)$ was calculated using the equation:

$$
L_{B}=\frac{B_{L}^{\prime}-B_{D}}{B_{L}^{\prime}} \times 100 \%
$$

DBL as fraction of production in the previous light period $\left(L_{P}\right)$ :

$$
L_{P}=\frac{B_{L}{ }^{\prime}-B_{D}}{B_{L}{ }^{\prime}-B_{D}{ }^{\prime}} \times 100 \%
$$

where $B_{L}{ }^{\prime}$ - culture density at the end of the previous light period, $B_{D}$ - culture density at the end of dark period, $B_{D}{ }^{\prime}$ - culture density at the end of the previous dark period (Qiang, Guterman, \& Richmond, 1996).

\section{Pigment measurements}

Pigments content was determined with spectrophotometric method. Chlorophylls and carotenoids were extracted from the cells with $100 \%$ acetone (CP, AO "Ekos"-1, Russia). Pigment extracts specters were registered by SF-2000 spectrophotometer (ZAO "OKB SPECTR», SaintPetersburg, Russia) in the wavelength range of 400 to $800 \mathrm{~nm}$ with $0,1 \mathrm{~nm}$ pitch. Chlorophyll $a(\mathrm{Ch} / \mathrm{a})$ and carotenoids ( $\mathrm{Car}$ ) concentrations were calculated by the equations proposed by Wellburn (1994), using optical density values at the wavelengths corresponding to the absorbance maximums of the pigments:

$$
\begin{aligned}
& \qquad h l a=11.75 \times\left(\mathrm{A}_{662}\right)-2.35 \times\left(\mathrm{A}_{645}\right) ; \\
& C h / b=18.61 \times\left(\mathrm{A}_{645}\right)-3.96 \times\left(\mathrm{A}_{662}\right) ; \\
& \text { Car }=\left(1000 \times \mathrm{A}_{470}-2.27 \times \text { Chla }-81.4 \times C h / b\right) / 227 ; \\
& \text { where A is absorbancy. }
\end{aligned}
$$

\section{Statistical Analyses}

Statistical data analysis was performed by standard Microsoft Excel software. Arithmetic mean $(\bar{x})$, standard deviation (S), error of the mean, confidence intervals for the mean $(\Delta \bar{x})$ were estimated. All calculations were made for the significance value $\alpha=$ 0,05 . The mean and confidence intervals $(\bar{x} \pm \Delta \bar{x})$ are given in the text and at the diagrams.

\section{Results}

\section{The "Green" Phase}

D. salina biomass and cell density buildup tool place in the course of the first "green" cultivation phase. The conditions were created to allow high growth and cell division rates. Initial cell density was $0.23 \cdot 10^{6} \mathrm{cell} / \mathrm{ml}$ that corresponded to $0.53 \mathrm{~g} / \mathrm{l}$ culture density. Exponential growth phase was absent, the batch growth curve started with linear phase (Figure $2 \mathrm{~A}$ ). D. salina culture density dynamics during the first growth phase mainly correlated to cell density dynamics. Culture density increased by a factor of 2.2 during the first 11 days. The maximal culture density value was $1.2 \mathrm{~g} / \mathrm{l}$. The maximal cell density was registered at $13^{\text {th }}$ day making $1,69 \cdot 10^{6} \mathrm{cell} / \mathrm{ml}$. The maximal productivity was $\left(P_{m}\right) 0.15 \cdot 10^{6} \mathrm{cell} /(\mathrm{ml} \cdot \mathrm{day})$ by cell density and $0.08 \mathrm{~g} /(1 \cdot$ day $)\left(7 \mathrm{~g} /\left(\mathrm{m}^{2}\right.\right.$.day $)$ by dry weight. $D$. salina cell density decreased gradually after $13^{\text {th }}$ cultivation day and it decreased by $29 \%$ at the end of "green" stage. Culture biomass during this period was 


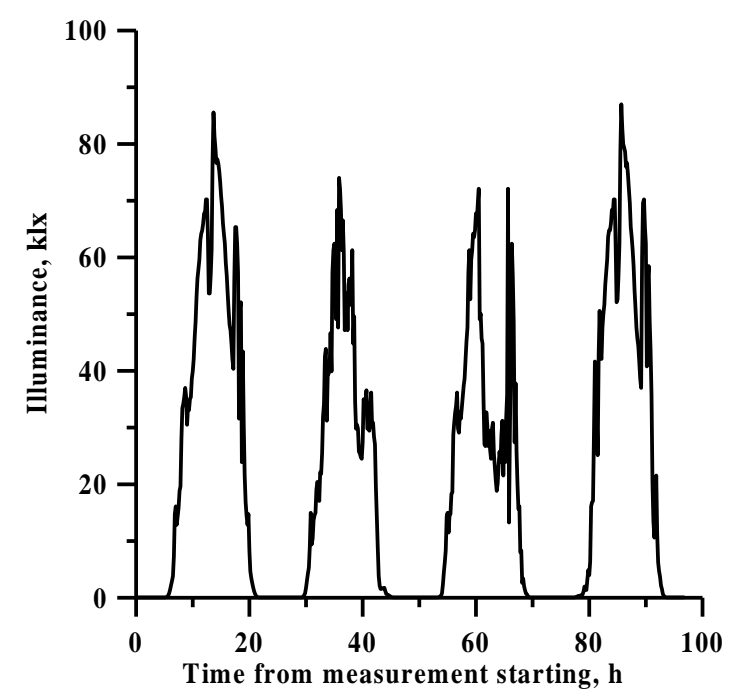

Figure 1. Diurnal variations of ponds surface illuminance during four days of experiment.
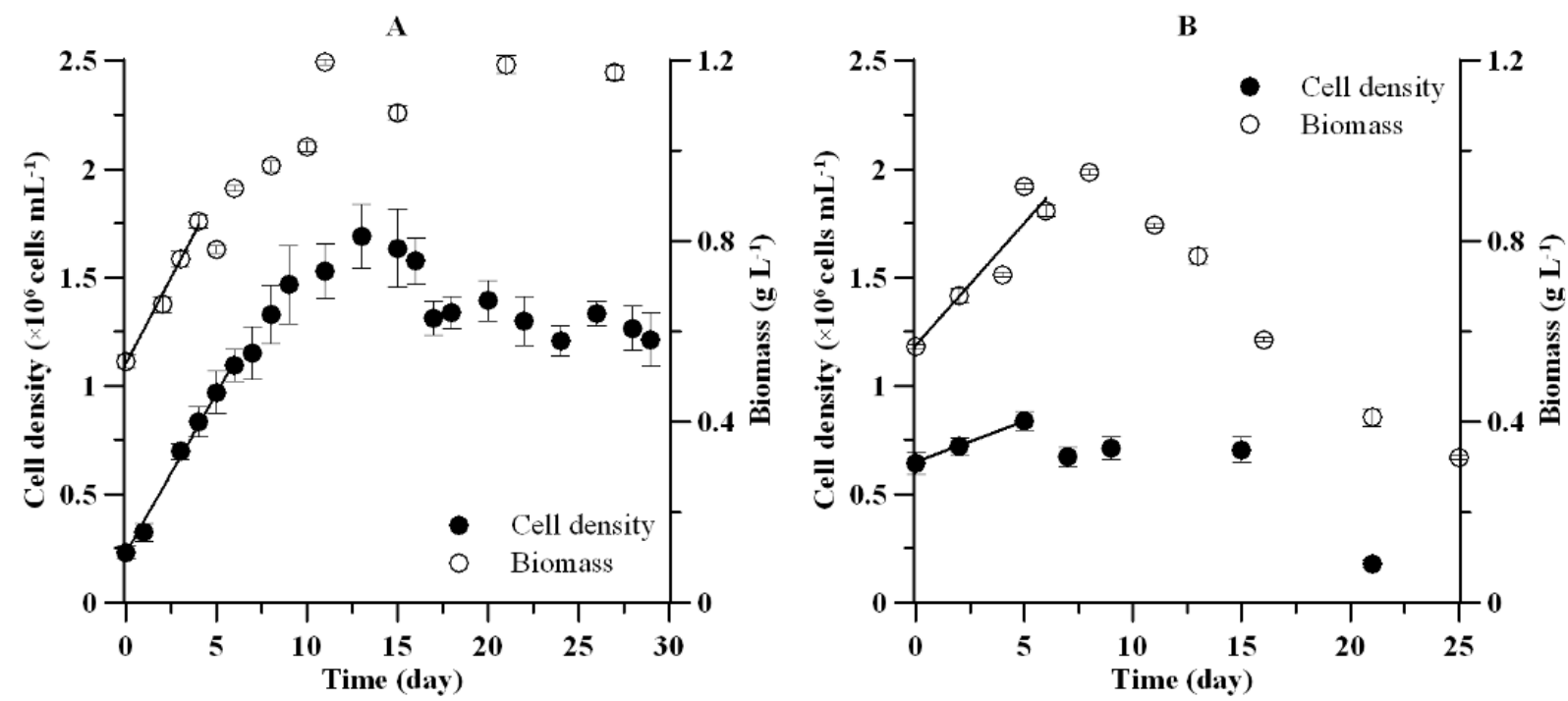

Figure 2. The dynamics of biomass and cell density at the "green" (A) and at the "red" (B) stages of cultivation.

more stable with values at the level of $1.2 \mathrm{~g} / \mathrm{l}$ (Figure 2 A).

Biomass and cell density growth was accompanied by pigments contents increase, both chlorophyll and carotenoids (Figure 3). It should be noted that Car/Chla ratio was high enough at the beginning of cultivation $(\mathrm{Car} / \mathrm{Chla}=11)$ as we used "red" phase culture as inoculum. Pigments ratio had markedly decreased (to 4) by the $3^{\text {rd }}$ day already. The ratio was within the limits of 2-2.5 from the $8^{\text {th }}$ day to the end of the phase. Such values correspond with "green" Dunaliella form grown on the medium used in the experiment and applied for commercial cultivation of this species (Shaish et al., 1990). Further $D$. salina culture passed into stationary growth phase and biomass and carotenoids accumulation stopped. This usually indicates that some of cultivation parameters becomes limiting.

Morphological changes in D. salina cells at "green" phase were registered as well. As we used "red" phase culture as inoculum, cells had both orange and green colouration and round shape at the beginning of the experiment (Figure 4 A). After fresh nutrient medium addition active growth started that resulted in intensification of green colouration. Also, cells became more drop-shaped, pyrenoid was more clearly visible, cell sizes decreased. In the course of culture growth and senescence after the $10^{\text {th }}$ day (phase of growth declining and stationary phase) cells acquired more oval shape and orange colour shade again (Figure $4 \mathrm{~A}$ ).

\section{The "Red" Phase}

Since the light factor is one of the main factors for carotenogenesis induction in D. salina (Ben-Amotz, 1995), we applied earlier approved method for increasing culture cells irradiance level at the second cultivation stage. The method included culture dilution twofold and reduction of culture layer depth by $55 \%$ 
(Borovkov \& Gudvilovich, 2017) that allowed increasing microalgae cells irradiance level by a factor of 4.5. Macronutrient limitation was created also, as the nutrient medium added lacked nitrogen and phosphorus salts.

D. salina cell density at the second "red" cultivation phase increased by $25 \%$ during the first 5 days of cultivation. The maximum value at this time was $0.84 \cdot 10^{6} \mathrm{cell} / \mathrm{ml}$ (Figure $2 \mathrm{~B}$ ). Culture density increased also at this period of time, reaching the maximum value of $0.95 \mathrm{~g} / \mathrm{l}$ by the $8^{\text {th }}$ day of cultivation. The calculated maximal productivity $\left(P_{m}\right)$ was $0,04 \cdot 10^{6} \mathrm{cell} /(\mathrm{ml} \cdot$ day $)$ on the cell density basis and $0.05 \mathrm{~g} /(\mathrm{l} \cdot$ day $)$ by biomass. This process was accompanied by the raise of carotenoids content in the culture, which increased twice compared to initial values. Carotenoids content amounted to 20 $\mathrm{mg} / \mathrm{l}$ or $800 \mathrm{mg} / \mathrm{m}^{2}$ at the $13^{\text {th }}$ day of the red phase (Figure 3 B). The average apparent carotenoid accumulation rate during this period was 0.65 $\mathrm{mg} /(\mathrm{l} \cdot \mathrm{day})$. By the end of the second phase cell density decreased by a factor of 4.6 , and culture density and carotenoids content diminished more than 5 times (Figure 2 B; 3 B). Car/Chla pigments ratio started to rise steadily after the $8^{\text {th }}$ day of the red phase. By the end of cultivation this ratio was equal to 11.6 , that was more
A

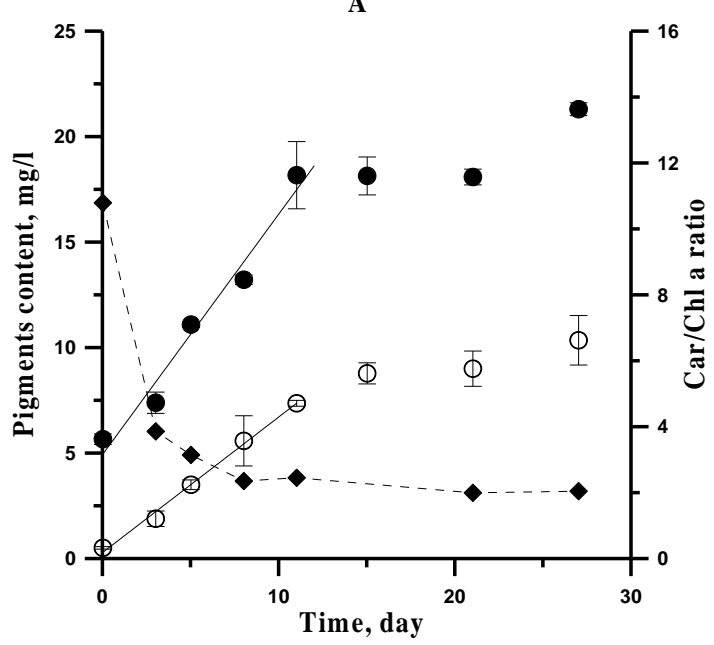

B

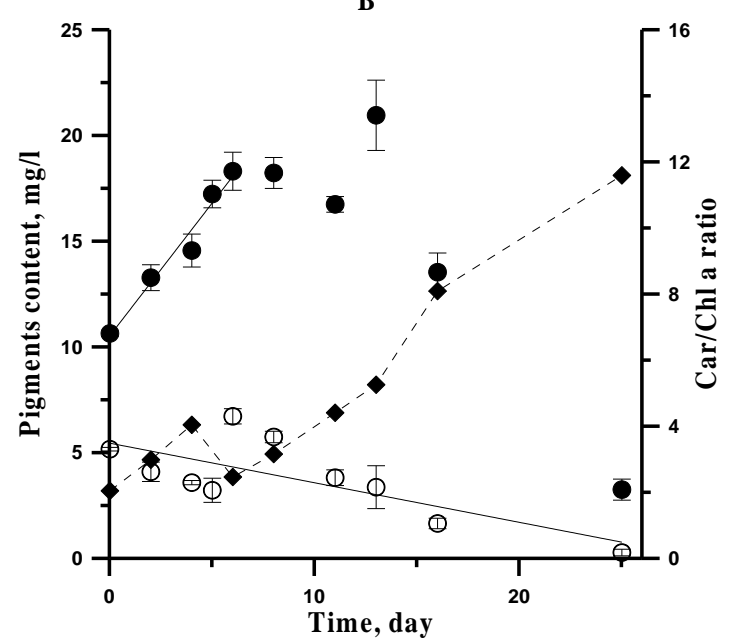

Figure 3. The dynamics of carotenoids $(\bullet)$, chlorophyll $a(0)$ content and Car/Chl $a$ ratio $(\mathbb{D} D)$ at the "green" cultivation stage (A) and at the "red" cultivation stage (B).

A

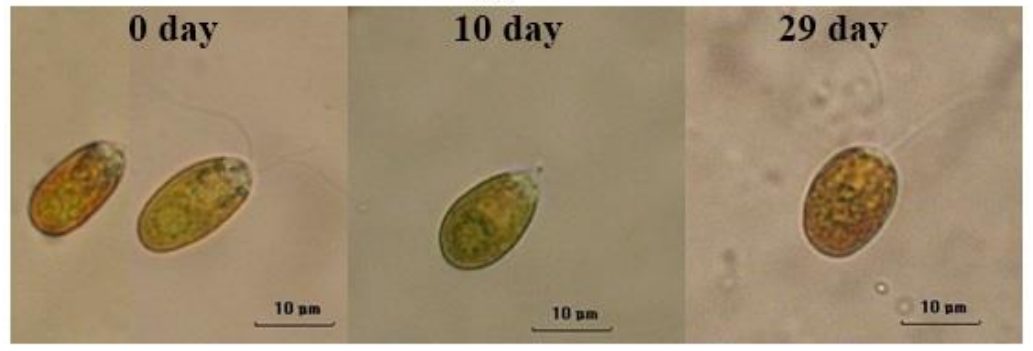

B

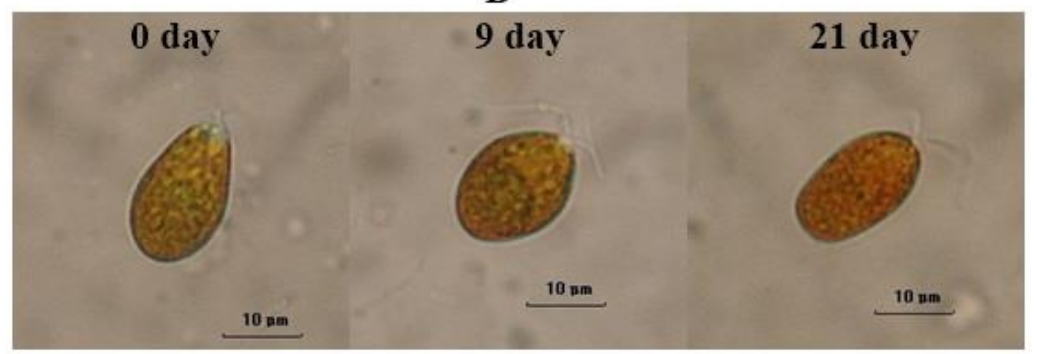

Figure 4. Morphology and colouration changes of D. salina cells at "green" (A) and "red" (B) cultivation phase. Scale bar is $10 \mu \mathrm{m}$. 
than 5 times higher compared to its value at the beginning of the phase (Figure $3 \mathrm{~B}$ ).

Significant changes in cell morphology were noted at the "red" stage, under stress conditions for $D$. salina growth and development (Figure 4 B). Granulation of cell contents, which was present in their structure at the beginning of the second stage in the form of coloured lipid globules, became pronounced by the 9th day and was further intensified until the end of the experiment. $D$. salina cells acquired saturated orange and tile-red colouration, became more rounded and increased in size (Figure $4 \mathrm{~B}$ ).

\section{Night Biomass Loss}

Night biomass loss (NBL) determination in D. salina culture was carried out to define relation between average daily productivity and dark losses due to algal culture respiration. The loss parameters were determined at the linear growth phase, which is characterized by the maximum productivity. NBL in the "green" culture was 5.3-5.6\% of biomass, while in the "red" phase it was higher, amounting 7.3-9.5\% of biomass. The value of NBL as fraction of production in the previous light period varied more amounting to 41.4-57.9\% for the "red" variant and 15.2-29.5\% for the "green" variant of $D$. salina culture.

\section{Discussion}

Various conditions in the first and second phases determine the peculiarities of physiological, biochemical and production characteristics of $D$. salina at its twophase cultivation. It is worth noting that the linear growth of $D$. salina culture in the second phase (which was observed in our experiment) does not always occur, because the purpose of this stage is carotenogenesis induction under the influence of stress factors (the main are light factor and mineral nutrient deficiency). In practice, under natural illumination, photostress level is difficult to be adjusted. Throughout the entire period of the experiment, alternating solar and cloudy days were observed, with daily light energy value differing up to 1.4 times (Figure 1). Despite the fact that the experiment was carried out in June-July, when the photoperiod and solar radiation level in Crimea is quite high (Massyuk, 1973; Chekushkin et al., 2018), part of the cloudy days fell on the first days of the second cultivation phase. Such conditions led to an increase in both cell number and culture density in the first 6 days. D. salina culture could use residual amounts of mineral nutrients, as well as intracellular nitrogen reserves for its growth in the second phase, as the chlorophyll a content, which forms pigment-protein complexes, decreased to almost zero values by the end of the phase, and the observed pigment synthesis rate had negative values $(-0.19$ $\mathrm{mg} /($ (lday)) (Figure $3 \mathrm{~B}$ ).

Morphological changes as a distinct granulation in the cell structure and the acquisition of saturated orange and tile-red coloration coincide in time with an increase in carotenoids contents level and the ratio of Car/Chla in the algae suspension (Fig 3 B). Therefore, the change in cell coloration may serve as an additional marker of 8 -carotene content change in the culture.

Based on data analysis on the changes in the physiological and biochemical parameters of $D$. salina culture during its two-stage cultivation in the greenhouse complex, the optimal duration of the $1^{\text {st }}$ and $2^{\text {nd }}$ stages was about 10-12 days for each stage. It is by 10-12 days that cell density and biomass and carotenoids accumulation in cultivators are close to the maximum values at each stage (Figure $2 \mathrm{~A}, \mathrm{~B} ; 3 \mathrm{~A}, \mathrm{~B}$ ). After 10 days at the 2 nd stage, there was a decrease in cell density and a significant decrease in $D$. salina culture density by 2.4 times as a result of stress factors. The increase in the 1 st and 2 nd stages duration over 15 days in the conditions of the experiment is impractical, because at the "green" stage further biomass growth (increase in the number of cells) does not occur in this period, and at the "red" stage there is a significant reduction in the cell density (4 times), biomass (2.4 times) and the Car content in the culture (6 times) (Figure 1, 2).

Eventually, the calculations showed that the average $D$. salina productivity was $4 \mathrm{~g} /\left(\mathrm{m}^{2}\right.$.day) for 11 days of cultivation at the "green" stage, and the average carotenoids accumulation rate was $37.5 \mathrm{mg} /\left(\mathrm{m}^{2}\right.$.day) for 11 days at the "red" stage. As a result, algae biomass containing $3 \mathrm{~g}$ of carotenoids can be obtained from $1 \mathrm{~m}^{2}$ $(100$ I) of starter culture during the 20-22-day technological cycle.

Night biomass loss was approximately 2 times higher in the "red" phase compared to the "green phase", both as a fraction of biomass and a fraction of daytime production. It is known that slowdown of metabolic processes occurs at the "red" stage of $D$. salina cells development, caused by mineral nutrients deficiency. However, higher NBL value suggests higher cell respiration rate than at the "green" stage. This difference between the variants may be due to the difference in the biochemical cell composition and to the reserve compounds content, which serve as substrate for dark respiration. The "red" stage is characterized by lipids and polysaccharides accumulation, which in turn can lead to an increase in respiration rate, the ratio of catabolic losses in the daily metabolic balance and an additional decrease in observed productivity.

The excretion of exometabolites into the medium can contribute additionally to a higher level of biomass losses at the "red" stage. It is known that organic carbon excretion in $D$. salina increased under unfavorable conditions, such as salinity rise and lack of nitrate nitrogen (Giordano et al., 1994).

Based on the results obtained, it can be recommended to consider minimum NBL level to be about 5\% of biomass for actively growing "green" culture. NBL value for "red" stage culture is about $10 \%$ 
of biomass. NBL as a fraction of production depends significantly on the growth stage and culture productivity at the moment and is not stable over the course of batch growth.

\section{Conclusion}

In the course of two-phase cultivation of carotenogenic microalgae $D$. salina in the south-west of the Crimean Peninsula, its physiological and biochemical characteristics were studied and its production potential was determined. The optimal duration of the first and second cultivation stages to obtain the maximum yield of biomass and carotenoids was determined. The data obtained in the experiment, on the rates of biomass and pigments accumulation, indicate the possibility of obtaining up to $3 \mathrm{~g}$ of carotenoids from $1 \mathrm{~m}^{2}$ of initial Dunaliella culture during the technological cycle of 20 25 days. $D$. salina night biomass loss at the "green" and "red" culture growth stages was assessed; the relevance of taking this parameter into account when organizing industrial Dunaliella cultivation and evaluating its productivity was shown. Further experimental studies to determine the production characteristics of $D$. salina depending on the seasonal variability of weather factors are of interest. In general, it was shown that the Crimean Peninsula is a promising region for the development of D. salina cultivation technology.

\section{Acknowledgements}

This study was funded by Russian Foundation for Basic Research and the Government of Sevastopol according to the research project №18-44-920009 and by the state research project of A.O. Kovalevsky Institute of Biology of the Southern Seas of RAS № 0828-20180004.

\section{References}

Absher, M. (1973). Hemocytometer Counting. In Paul F. Kruse Jr. \& M. K. Patterson Jr. (Eds.), Tissue Culture: Methods and Applications (pp. 395-397). New York, USA, Academic Press., 896 pp. https://doi.org/10.1016/B9780-12-427150-0.50098-X

Achour, H.Y., Doumandji, A., Bouras, N., Sabaou, N., \& Assunção, P. (2019). Isolation, Molecular Identification and The Carotenogenesis Process of the Microalgae Dunaliella salina Strain DunaDZ1 Isolated from an Algerian Salt Lake. Turkish Journal of Fisheries and Aquatic Sciences, $19 \quad$ (5), 399-407. http://doi.org/10.4194/1303-2712-v19_5_05

Avsiyan, A.L. (2014) Dynamics of culture density and dissolved organic substance at cultivation of the microalga Dunaliella salina in conditions of light-dark cycle. Bulletin of Nikitsky Botanical Garden, 111, 21-26 (in Russian)

Ben-Amotz, A. (1995). New mode of Dunaliella biotechnology: two-phase growth for $\beta$-carotene production. Journal of applied phycology, 7(1), 65-68. https://doi.org/10.1007/BF00003552

Ben-Amotz, A. (2003). Industrial Production of Microalgal Cell Mass and Secondary Products Major Industrial Species: Dunaliella. Handbook of Microalgal Culture: Biotechnology and Applied Phycology, 273-280. https://doi.org/10.1002/9780470995280.ch13

Ben-Amotz, A., Polle, J.E., \& Rao, D.S. (2009). The alga Dunaliella: biodiversity, physiology, genomics and biotechnology. Enfield, NH, Science Publishers, 555 pp.

Bonnefond, H., Moelants, N., Talec, A., Bernard, O., \& Sciandra, A. (2016). Concomitant effects of light and temperature diel variations on the growth rate and lipid production of Dunaliella salina. Algal research, 14, 72 78. https://doi.org/10.1016/j.algal.2015.12.018

Borovkov, A.B., Gudvilovich, I.N. (2017). The testing of twostage system of semi-industrial cultivation of Dunaliella salina Teod. Voprosy sovremennoy algologii, 13 (1). (In Russian) Available at: http://algology.ru/1155 (accessed 13.06.2019).

Borovkov, A.B., Gudvilovich, I.N. (2015). Intensive cultivation of Dunaliella salina as way of obtaining of biomass with elevated $\beta$-carotene content. Communication 2. Optimization of Cultivation Regime. Hydrobiological $\begin{array}{llll}\text { Journal, } & 51 & \text { (4), }\end{array}$ https://doi.org/10.1615/HydrobJ.v51.i4.40

Borowitzka, M. A. (2013). Dunaliella: biology, production, and markets. Handbook of Microalgal Culture: Applied Phycology and Biotechnology, 359-368. https://doi.org/10.1002/9781118567166.ch18

Chekushkin A.A., Lelekov A.S., Trenkenshu R.P. (2018) Automatic sensor registration circadian variation of illuminance in the Sevastopol region. Aktualnye voprosy biologicheskoy fiziki i himii, 3(3), 547-552. (in Russian)

Del Campo, J. A., García-González, M., \& Guerrero, M. G. (2007). Outdoor cultivation of microalgae for carotenoid production: current state and perspectives. Applied microbiology and biotechnology, 74(6), 1163-1174. https://doi.org/10.1007/s00253-007-0844-9

García-González, M., Moreno, J., Manzano, J. C., Florencio, F. J., \& Guerrero, M. G. (2005). Production of Dunaliella salina biomass rich in 9-cis-betacarotene and lutein in a closed tubular photobioreactor. Journal of Biotechnology, 115, 81-90. https://doi.org/10.1016/j.jbiotec.2004.07.010

García-González, M., Moreno, J., Canavate, J. P., Anguis, V., Prieto, A., Manzano, C., ... \& Guerrero, M. G. (2003). Conditions for open-air outdoor culture of Dunaliella salina in southern Spain. Journal of Applied Phycology, 15(2-3),

177-184. https://doi.org/10.1023/A:1023892520443

Gevorgiz, R. G., Alisievich, A. V., \& Shmatok, M. G. (2005). Estimation of biomass Spirulina platensis (Nordst.) Geitl with use of optical density of culture. Ekologiya Morya, 70, 96-106.

Giordano, M., Davis, J. S., \& Bowes, G. (1994). Organic carbon release by Dunaliella salina(Chlorophyta) under different growth conditions of $\mathrm{CO}_{2}$, nitrogen, and salinity. Journal of Phycology, 30(2), 249-257. https://doi.org/10.1111/j.0022-3646.1994.00249.x

Hamed, I., Ak, B., Isık, O., \& Uslu, L. (2017). The Effects of Salinity and Temperature on the Growth of Dunaliella sp. Isolated from the Salt Lake (Tuz Gölü), Turkey. Turkish 
Journal of Fisheries and Aquatic Sciences, 17, 1367-1372. http://doi.org/10.4194/1303-2712-v17_6_29

Kilic, N.K., Erdem, K., \& Donmez, G. (2019). Bioactive Compounds Produced by Dunaliella species, Antimicrobial Effects and Optimization of the Efficiency. Turkish Journal of Fisheries and Aquatic Sciences, 19 (11), 923-933.

http://doi.org/10.4194/1303-2712 v19_11_04

Kitto, M. R., \& Resinald, M. (2011). Effect of summer/winter light intensity and salt on growth kinetics and beta carotene accumulation by Dunaliella in open outdoor earthern ponds in a desert island, off UAE coast. Journal of Algal Biomass Utilization, 2, 14-21.

Lamers, P. P., Janssen, M., De Vos, R. C., Bino, R. J., \& Wijffels, R. H. (2012). Carotenoid and fatty acid metabolism in nitrogen-starved Dunaliella salina, a unicellular green microalga. Journal of biotechnology, 162(1), 21-27. https://doi.org/10.1016/j.jbiotec.2012.04.018

Lelekov, A. S., \& Trenkenshu, R. P. (2007). Simplest models of microalgae growth 4. Exponential and linear growth phases of microalgae culture. Ekologiya Morya, 74, 4749. (in Russian)

Lv, H., Cui, X., Wahid, F., Xia, F., Zhong, C. \& Jia, S. (2016). Analysis of the Physiological and Molecular Responses of Dunaliella salina to Macronutrient Deprivation. PLOS ONE, $\quad 11 \quad$ (3): $\quad$ e0152226. https://doi.org/10.1371/journal.pone.0152226

Massyuk, N.P. (1973). Morphology, Taxonomy, Ecology and Geographic distribution of the Genus Dunaliella Teod. and prospectus for its potential utilization. Kiev, Naukova Dumka Press., 487 pp. (In Russian).

Minhas, A. K., Hodgson, P., Barrow, C. J., \& Adholeya, A. (2016). A review on the assessment of stress conditions for simultaneous production of microalgal lipids and carotenoids. Frontiers in microbiology, 7, 546. https://doi.org/10.3389/fmicb.2016.00546

Oren, A. (2005) A hundred years of Dunaliella research: 19052005. Saline Systems, 1 (1), 2. https://doi.org/10.1186/1746-1448-1-2

Peel, M. C., Finlayson, B. L., \& McMahon, T. A. (2007). Updated world map of the Köppen-Geiger climate classification. Hydrology and earth system sciences discussions, 4(2), 439-473. https://doi.org/10.5194/hess-11-1633-2007

Polle, J. E., \& Melis, A. (1999). Recovery of the photosynthetic apparatus from photoinhibition during dark incubation of the green alga Dunaliella salina. Functional Plant Biology, 26(7), 679-686. https://doi.org/10.1071/PP99004

Prieto, A., Canavate, J. P., \& García-González, M. (2011). Assessment of carotenoid production by Dunaliella salina in different culture systems and operation regimes. Journal of biotechnology, 151(2), 180-185. https://doi.org/10.1016/j.jbiotec.2010.11.011
Qiang, H., Guterman, H., \& Richmond, A. (1996). Physiological characteristics of Spirulina platensis (Cyanobacteria) cultured at ultrahigh cell densities. Journal of Phycology, 32(6), 1066-1073. https://doi.org/10.1111/j.00223646.1996.01066.x

Sathasivam, R., \& Ki, J. S. (2018). A review of the biological activities of microalgal carotenoids and their potential use in healthcare and cosmetic industries. Marine drugs, 16(1), 26. https://doi.org/10.3390/md16010026

Shaish, A., Avron, M., \& Ben-Amotz, A. (1990). Effect of inhibitors on the formation of stereoisomers in the biosynthesis of $\beta$-carotene in Dunaliella bardawil. Plant and cell physiology, 31(5), 689-696. https://doi.org/10.1093/oxfordjournals.pcp.a077964

Solovchenko, A. E., Selivanova, E. A., Chekanov, K. A., Sidorov, R. A., Nemtseva, N. V., \& Lobakova, E. S. (2015). Induction of secondary carotenogenesis in new halophile microalgae from the genus Dunaliella (Chlorophyceae). Biochemistry (Moscow), 80 (11), 15081513. https://doi.org/10.1134/S0006297915110139

Tafreshi, A. H., \& Shariati, M. (2006). Pilot culture of three strains of Dunaliella salina for $\beta$-carotene production in open ponds in the central region of Iran. World Journal of Microbiology and Biotechnology, 22, 1003-1006. https://doi.org/10.1007/s11274-006-9145-1

Terez, E. I., Terez, G. A., Kozak, A. V., Kuzmin, S. V., \& Dolgii, S. O. (2012). The study of atmospheric optical parameters according to multiyear photometric observations of the sun in Crimea. Bulletin of the Crimean Astrophysical Observatory, 108(1), 146-157. https://doi.org/10.3103/S0190271712010214

Tran, D., Doan, N., Louime, C., Giordano, M., \& Portilla, S. (2014). Growth, antioxidant capacity and total carotene of Dunaliella salina DCCBC15 in a low cost enriched natural seawater medium. World Journal of Microbiology and Biotechnology, 30(1), 317-322. https://doi.org/10.1007/s11274-013-1413-2

Wellburn, A. R. (1994). The spectral determination of chlorophylls $a$ and $b$, as well as total carotenoids, using various solvents with spectrophotometers of different resolution. Journal of plant physiology, 144(3), 307-313. https://doi.org/10.1016/S0176-1617(11)81192-2

Wu, Z., Dejtisakdi, W., Kermanee, P., Ma, C., Arirob, W., Sathasivam, R., \& Juntawong, N. (2017). Outdoor cultivation of Dunaliella salina KU 11 using brine and saline lake water with raceway ponds in northeastern Thailand. Biotechnology and applied biochemistry, 64(6), 938-943. https://doi.org/10.1002/bab.1537

Xu, Y., Ibrahim, I. M., \& Harvey, P. J. (2016). The influence of photoperiod and light intensity on the growth and photosynthesis of Dunaliella salina (Chlorophyta) CCAP 19/30. Plant Physiology and Biochemistry, 106, 305315. https://doi.org/10.1016/j.plaphy.2016.05.021 